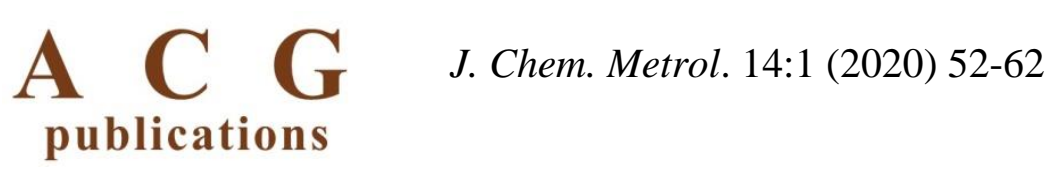

journal of chemical metrology

\title{
Development of a densitometric HPTLC method for determination of 5-HMF in fruit-based baby foods in Turkey Zeynep Turkmen (i)*
}

\author{
Istanbul University-Cerrahpasa, Institute of Forensic Sciences and Legal Medicine, 34500, \\ Hadimkoy Campus, Buyukcekmece, Istanbul, Türkiye
}

(Received April 27, 2020; Revised May 30, 2020; Accepted June 04, 2020)

\begin{abstract}
This study reports the determination of 5-hydroxymethylfurfural (5-HMF) by HPTLC in fruit-based baby food products and compares the other techniques. The performance of QuEChERS method was evaluated for the measurement of 5-HMF. The mean recovery and RSD\% at the two-fortification level of 25 and $250 \mathrm{ng} / \mathrm{spot}$ were $83.65 \%$ and $2.0 \%$, and $96.02 \%$ and $3.0 \%$, respectively. LOD and LOQ levels for 5-HMF were found 1.54 $\mathrm{ng} / \mathrm{spot}$ and $4.67 \mathrm{ng} / \mathrm{spot}$ in fruit-based baby foods, respectively. Fifty eight commercial products on the Istanbul market were evaluated by developed and validated HPTLC method and, 5-HMF were determined in $48(82.76 \%)$ in the range of $13.12-28.90 \mathrm{mg} / \mathrm{kg}$. Although the concentration of $82.76 \%$ of the 5 -HMF detected products was found to be below the legal limit, the results revealed that a new regulation should be made in fruit-based food considering the baby exposure limit. The analytical performance of this method verifies its potential applicability with particularly low cost and simple sample pretreatment.
\end{abstract}

Keywords: Baby food; 5-hydroxymethylfurfural; HPTLC; method validation; QuEChERS. () 2020 ACG Publications. All rights reserved.

\section{Introduction}

Foodborne contaminants in nutrition, whether microbiological or chemical, are a major concern for customers. Presence of this kind of contamination in baby products triggers concerns of food safety in the public. Serious efforts have been made to investigate sources of contamination, especially on marketed baby foods.

It is known that a variety of factors during processing affect the quality of the final product. This process starts from receiving of the raw material until the product reaches the consumer. The most common occurrence of foodborne contaminants is the thermal step by combining the product with other components at high temperature [1]. Neo-formed contaminants (NFCs) are compounds forming during thermal or preservation processes and exhibiting possible harmful effects to humans. It is seen that acrylamide and 5-hydroxymethylfurfural (5-HMF) have attracted the attention of the scientific community to evaluate the average exposure in different populations in recent years [2]. It is known that $5-\mathrm{HMF}$ is a furanic compound that can be formed by Maillard reaction or hexose dehydration in acid media. It is reported that 5-HMF formation is depend on mostly temperature, sugar type, $\mathrm{pH}$, water activity and divalent cations concentrated in media. It is also known that it has established genotoxic, mutagenic or carcinogenic activities [2-4], due to $\alpha$, ß-unsaturated carbonyl groups and allylic hydroxyl

\footnotetext{
*E-Mail: zeytur@gmail.com
} 
groups. Therefore, toxicity testing of 5-HMF is very important to ensure that the maximum levels are not exceeded in food products even in baby foods or expired baby cough syrups [5].

Today, due to factors such as technological developments, rapid urbanization and intense work tempo, it is seen that ready-made foods replace natural nutrition [6]. Unfortunately, this situation affects parents, who work hard for a long time. Due to their size, physiology, and behavior, children are more sensitive than adults to toxins. Also, chronic exposure of contaminants in food can deleteriously influence both their physical and mental development.

High Performance Thin Layer Chromatography (HPTLC) has become a modern analytical technique due to the minimization of conventional errors of Thin Layer Chromatography (TLC). It is easy serving low quantitative analysis with specialized plates with reduced sample diffusion resulting in compact bands or spots. The new compartments continue to give the device new abilities such as scanning, full optimization, selective detection principle, minimum sample preparation, hyphenation [79]. Combining densitometer and/or mass detectors besides plate variety offers outstanding throughput and applicability especially in forensic and food chemistry [9-14].

Different analytical methods were used for the determination of 5-HMF in extensive range of foods and extraction techniques by using chromatographic methods such as TLC [15], HPTLC [16,17], high-performance liquid chromatography (HPLC) [18,19], liquid chromatography mass spectrometry (LC-MS) [20], capillary electrophoresis (CE) [21], micellar electrokinetic capillary chromatography (MECK) [22], gas chromatography-mass spectrometry (GC-MS/MS) [23], and nuclear magnetic resonance spectroscopy (NMR) [24].

Legal limits for 5-HMF content in honey were determined by consulting the Codex Committee as $40 \mathrm{mg} / \mathrm{kg}$. Also, the Turkish Standards Institute (TSE) has allowed $50 \mathrm{mg} / \mathrm{kg}$ and $75 \mathrm{mg} / \mathrm{kg}$ concentration levels for matrices such as pomegranate syrup and grape molasses, respectively [25,26]. However, the toxicological relevance of 5-HMF in baby products besides regulation limit have not been clearly demonstrated nowadays.

Despite the fact that there are some determination methods of 5-HMF in several food matrices (honey, jams, syrup, beverages, molasses etc) [11-24, 27, 28] and also in baby foods (milk formulas, cereals, jams and puree) [29-33], to the best of its knowledge, this is the first validated method of 5HMF in fruit-based baby food products conducted by HPTLC after an efficient extraction by acidified QUECHERS.

The presented study is based on our group's previous study, which was to investigate the amount of patulin in 58 fruit-based baby food products [10]. After realizing existence of 5-HMF in baby foods, a study designed to evaluate the amounts of this toxic food-born product. Thus the aim of this study was to develop and validate an HPTLC method for determination of 5-HMF in fruit-based baby foods. Method validation and uncertainty evaluation of developed method were discussed and measurement results of title contaminant in baby foods in Istanbul reported herein.

\section{Experimental}

\subsection{Chemicals and Instrumentation}

Analytical standard of 5-HMF (99.0\% purity - H40807-5 mg, CAS 67-47-0) was purchased from Sigma Aldrich (St. Louis, MO, USA). Caffeine (99.0\% purity - C0750-5 mg, CAS 58-08-2) used as internal standard and ammonium acetate (A7262, $2.5 \mathrm{~kg}$, CAS 631-61-8) were also purchased from Sigma-Aldrich (St. Louis, MO, USA). Toluene, methanol, dichloromethane, ethyl acetate, and formic acid solutions were purchased from Merck (Germany). All the solvents used were of HPLC grade.

The HPTLC equipment used included Automatic TLC Sampler 4 (ATS4); Automatic Developing Chamber 2 (ADC-2); TLC Scanner 3 with winCATS software (version 1.4.2. 8121) (Camag, Muttenz, Switzerland); and pre-coated silica gel 60 F254 HPTLC glass plates with $200 \mu \mathrm{m}$ thickness, $20 \times 10 \mathrm{~cm}$, Cat. no. 1.05649 (Merck, Darmstadt, Germany). A Direct-Q3TM water system (Millipore, Bedford, MA, USA) was used in the laboratory to produce deionized water. QuEChERS Extraction Kit (Restek SPE Q-sep Q150) was used for a better efficiency. Techne - DB100/3 was also used for sample concentrator to remove solvents after extractions by evaporating. 


\subsection{Sample Collection and Processing}

The study was carried out using 58 fruit-based baby food products obtained from market in İstanbul between 2016 Autumn - 2017 Spring seasons. When the fruit content of the products were evaluated, $15.5 \%$ had only apple and $84.5 \%$ had apple mixed fruits such as peach, banana, carrot and blueberry. The studied samples were selected from 7 different commercial brands (Table S1).

The samples were kept at room temperature $\left(25 \pm 2{ }^{\circ} \mathrm{C}\right)$ for 48 hours and the bottles were carefully shaken for 3 minutes before sample intake. Then, 10 grams of the samples were taken from each product, kept at same temperatures and diluted with $5 \mathrm{~mL}$ of distilled water before extraction.

\subsection{Preparation of Stock and Calibration Standards}

Stock solution of 5-HMF in methanol was prepared to contain $1000 \mu \mathrm{g} / \mathrm{L}$ and then stored at $+4^{\circ} \mathrm{C}$. Calibration solutions were prepared by diluting the stock solution for 7 points as $10,25,50,100$, 250, 500 and $750 \mathrm{ng} / \mathrm{L}$, independently from each other and used for HPTLC. Caffeine stock solution $(250 \mu \mathrm{g} / \mathrm{L})$ as internal standard (IS) was prepared by the same way and added to all samples with 25 $\mathrm{ng} / \mathrm{spot}$ final concentration.

\subsection{Method Validation Studies and Sample Preparation}

For linearity studies, aforementioned calibration points were analyzed 3 times for each points and calibration curve was obtained according to linear regression analysis. Limit of Detection (LOD) and Limit of Quantitation (LOQ) were estimated as $3.3 \mathrm{\sigma} / \mathrm{slope}$ and $10 \mathrm{\sigma} / \mathrm{slope}$ of the calibration curve of the analyte, respectively, according to the 135th Guideline of the US Food and Drug Administration (FDA) [34]. Recovery, precision and repeatability of the method were checked out for two concentrations ( 25 and $250 \mathrm{ng} / \mathrm{spot}$ ) with 6 replicates. Ten grams of 5-HMF free fruit-based baby food (wet weight) was exactly weighed into a conical flask, and $1 \mathrm{~mL}$ of the reference standard solutions of 5 -HMF with an upper (250 ng/spot) and lower $(25 \mathrm{ng} / \mathrm{spot})$ concentration levels were added into separate samples. The flask was vigorously shaken for a few minutes to ensure homogeneity. The spiked samples were allowed to stand overnight at room temperature and then remixed prior to extraction.

\subsection{Extraction Optimization (Pure Acetonitrile and Acetic Acid $1 \%$ in Acetonitrile)}

Ten grams of sample (wet weight) were weighed; $10 \mathrm{~mL}$ of acetonitrile and $25 \mu \mathrm{L}$ of caffeine solution were added. One pack of QuAEChERS was added to each tube and vortexed for 1 minute. The tubes were then centrifuged for 5 minutes. After centrifugation, approximately $6 \mathrm{~mL}$ of supernatant was removed and transferred into a $15 \mathrm{~mL}$ flask. QuEChERS clean up powder was added to the tube and the mixture was vortexed for 3 minutes and centrifuged. The supernatant was removed and transferred to a new flask and gently evaporated to dryness under nitrogen. The residue was eluted by adding $1000 \mu \mathrm{L}$ of $\mathrm{MeOH}$ and analyzed by HPTLC system.

The above-mentioned QuEChERS extraction procedure was similarly applied to all samples once only by adding $100 \mu \mathrm{L}$ of $1 \%$ acetic acid solution.

\subsection{High Performance Thin Layer Chromatography (HPTLC) Conditions}

Prior to using, HPTLC plates $(10 \times 20 \mathrm{~cm})$ were washed with methanol to the top and then dried at $120{ }^{\circ} \mathrm{C}$ by drying oven for $20 \mathrm{~min}$. Sample extracts were applied on pretreated HPTLC plates with 8$\mathrm{mm}$ band-wide by ATS 4 (CAMAG, Switzerland) autosampler unit. According to automatically calculated layout of ATS, samples were applied 8-mm distance from the bottom and $12 \mathrm{~mm}$ from each side of plates $(25-\mu \mathrm{L}$ syringe volume). The plates were pre-conditioned for 3 min without soaking the plate into the mobile phase (toluene-ethyl acetate: formic acid (5:4:1, v/v)) in ADC-2 (CAMAG, 
Switzerland) development unit. After 3 min they were developed with the same mobile phase to $80 \mathrm{~mm}$ with a good separation, the plate was sufficiently dried at $60{ }^{\circ} \mathrm{C}$ for 3 min by ADC2 unit automatically.

The developed plates were scanned with the TLC Scanner 3 unit which is controlled by WinCATS software. Scanning parameters were as follows: $284 \mathrm{~nm}$ wavelengths with a deuterium lamp, $20 \mathrm{~nm}$ monochromatic bandwidth, $4.0 \mathrm{~mm} \times 0.10 \mathrm{~mm}$ slit dimension, $20 \mathrm{~mm} / \mathrm{s}$ scan speed, and the data resolution $100 \mu \mathrm{m}$ per step. Bands were quantified in single-wavelength reflectance mode and evaluation was carried out by measuring the peak areas with linear regression. Multi-wavelength scanning was performed in the range between $200-400 \mathrm{~nm}$ at $20 \mathrm{~nm} / \mathrm{s}$ with data resolution of $1 \mathrm{~nm}$ per step.

\section{Results and Discussion}

\subsection{Optimization of the Method}

Resolution of HMF and CAF were the best on pretreated HPTLC plates developed with a mixture of toluene-ethyl acetate: formic acid (5:4:1, v/v) to a migration distance of $80 \mathrm{~mm}$ (developing time $\sim 19 \mathrm{~min}$ ). The retardation factors (Rf value) of 5-HMF and CAF (IS) were recorded as (Rf) 0.46 $( \pm 0.02) \mathrm{min}$. and $0.41( \pm 0.02)$ min., respectively.

Our procedure for 5-HMF extraction from fruit-based baby food was optimized using acetonitrile as the solvent. Due to the fact that 5-HMF is more stable under acidic conditions [23], the effect of pure acetonitrile and acidified acetonitrile on extraction efficiency was studied. The study was performed by spiking of 25 and $250 \mathrm{ng} / \mu \mathrm{L} 5-\mathrm{HMF}$ in $10 \mathrm{~g}$ toxin free homogenized samples $(\mathrm{n}=6)$. After vortexed for $1 \mathrm{~min}$, the homogenate was subjected to the acetonitrile extraction with or without acetic acid solution.

The mean recovery and RSD without acetic acid at two-fortification level for 25 and 250 $\mathrm{ng} / \mathrm{spot}$ were found 74.6 and $4.0 \%$, and 87.3 and $3.0 \%$, with acetic acid at the two fortification level for 25 and $250 \mathrm{ng} / \mathrm{spot}$ were found $83.65 \%$ and $2.0 \%$, and $96.02 \%$ and $3.0 \%$, respectively. Based on the results, acidified QuEChERS (A-QuEChERS) method was chosen and the method validation was performed with this selected extraction method.

The QuEChERS has become an important extraction technique in contaminant and residue analysis of food, feeding stuff and different matrices [35]. Currently, a study has been reported choosing acidic QuEChERS for optimum recovery efficiency of 5-HMF in milk based dairy products [23]. Thus applicability of QuEChERS was investigated for the extraction of 5-HMF from fruit-based matrix, because it allows short extraction times, low solvent use, better extraction yields.

To check out the robustness of the method; different scanning speeds (20 and $5 \mathrm{~mm} / \mathrm{s}$ ) were tried and chromatograms were recorded. Also, development step was applied under two different relative humidity levels (36.2\% and 38.4\%). Robustness results were obtained and evaluated at two concentration levels of 25 and $250 \mathrm{ng} / \mathrm{spot}(\mathrm{n}=5)$. The results of the robustness study were represented in Table S2. The comparative chromatograms of the selected conditions for scan speed and relative humidity level were shown in Figure S1 and S2, respectively.

According to results, proper conditions were set as $20 \mathrm{~mm} / \mathrm{s}$ for scan speed and $36.2 \%$ for relative humidity. It was seen that lower scan speed $(5 \mathrm{~mm} / \mathrm{s})$ caused background noises and relative humidity must be kept under $36.2 \%$ for optimum conditions for the determination of 5-HMF (Table 1 and Table 2).

\subsection{Method Validation}

\subsubsection{Linearity}

Calibration curve of 5-HMF were established with seven concentration levels of the standard solution and were constructed by plotting the peak areas against the corresponding amounts of the 5HMF (10, 25, 50, 100, 250, 500 and $750 \mathrm{ng} / \mathrm{spot})$. The linear range of the method was found between $10-750 \mathrm{ng} / \mathrm{spot}$ as shown in Figure S3. The calibration plot for the compound was defined by the 
equation $y=7.084 x+209.826$ with five replicates of each calibration point. The $r$ value was found to be 0.997 (Figure S3) indicating a good linear relationship between peak areas.

\subsubsection{Recovery, Repeatability, and Intermediate Precision}

Detailed information about the recovery studies including two concentrations $(25-250 \mathrm{ng} / \mu \mathrm{L})$ was shown in Table 1. The relative standard deviations (RSD\%) of peak ratios were calculated to be less than 3. For each concentration, the standard deviation values of the reproducibility studies, which carried out 6 times, were found to be $\leq 3$, while the RSD \% values were found to be $\leq 3.59$ for $25 \mathrm{ng} / \mu \mathrm{L}$ and 2.08 for $250 \mathrm{ng} / \mu \mathrm{L}$.

\subsection{3. $L O D$ and $L O Q$}

Linearity range was satisfactory for analyses of 5-HMF in baby food products. In this method, the LOD and LOQ levels were calculated by standard deviation of the calibration curve. Under the optimized conditions, the LOD and LOQ levels for 5-HMF were found $1.54 \mathrm{ng} / \mathrm{spot}$ and $4.67 \mathrm{ng} / \mathrm{spot}$, respectively (Table S3). These values were suitable abundantly for the 5-HMF determination in fruitbased baby food products to check out the regulated concentration.

Table 1. Recovery and RSD data of the extraction method with acidified QuEChERS*

\begin{tabular}{|c|c|c|c|c|}
\hline Replicate & \multicolumn{2}{|c|}{$25 \mathrm{ng} / \mu \mathrm{L}$} & \multicolumn{2}{|c|}{$250 \mathrm{ng} / \mu \mathrm{L}$} \\
\hline & Recovery \% & RSD\% & Recovery\% & RSD\% \\
\hline 1 & 88.2 & & 96.2 & \\
\hline 2 & 81.7 & & 98.6 & \\
\hline 3 & 82.6 & 359 & 92.7 & 208 \\
\hline 4 & 82.5 & 3.59 & 97.2 & 2.08 \\
\hline 5 & 80.0 & & 95.1 & \\
\hline 6 & 86.9 & & 96.3 & \\
\hline
\end{tabular}

$\mathrm{n}=6$ for each concentration level

Although the incidence of adverse response of the body in food is very low, some food products contain toxins formed naturally due to their handling, processing and storage conditions. As an important food-born contaminant, 5-HMF, which is formed during thermal treatments applied to foods such as caramelization. In order to investigate 5-HMF contamination levels in various fruit-based baby products, an accurate HPTLC method with broad applicability was developed and validated in this study.

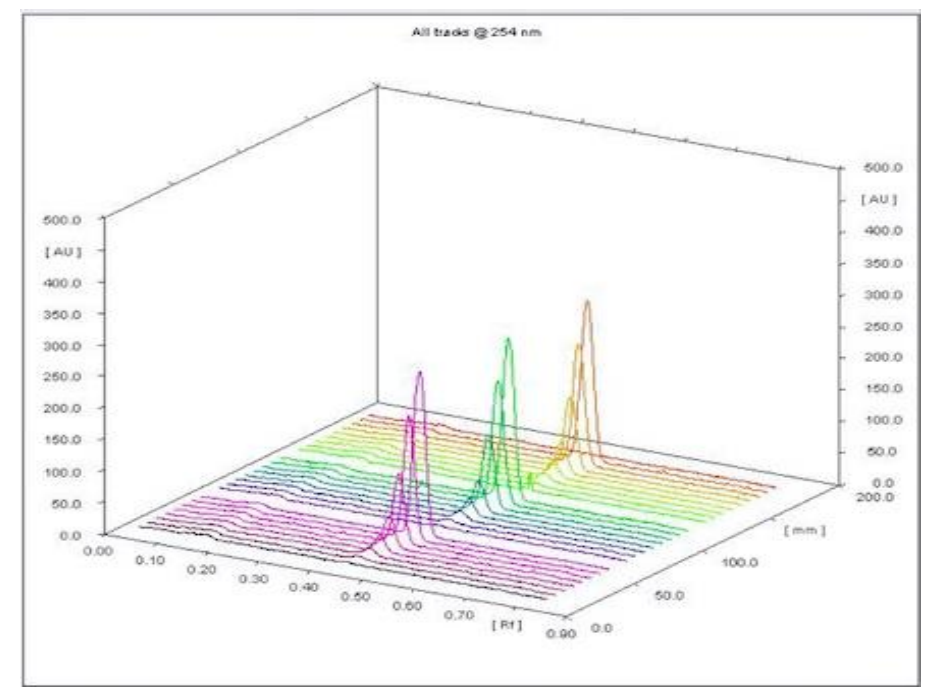

Figure 1. A 3D view of 5-HMF standard solutions in the linear range of the method 
There are several studies conducted to determine 5-HMF contamination with progressive techniques for years [11-24, 27-33]. Some recent ones were listed for a comparison in Table 3.

Concentration with respect to the peak area in the range of $10-750 \mathrm{ng} / \mathrm{spotwhich}$ has a little bit higher LOD but larger linear range than Hoštálková's study with a range of $4-60 \mathrm{ng} / \mathrm{spot} \mathrm{[16].} \mathrm{A} \mathrm{3D}$ view of all chromatograms of calibration solutions of 5-HMF was shown in Figure 1. Additionally, matrix effect was shown in Figure 2.

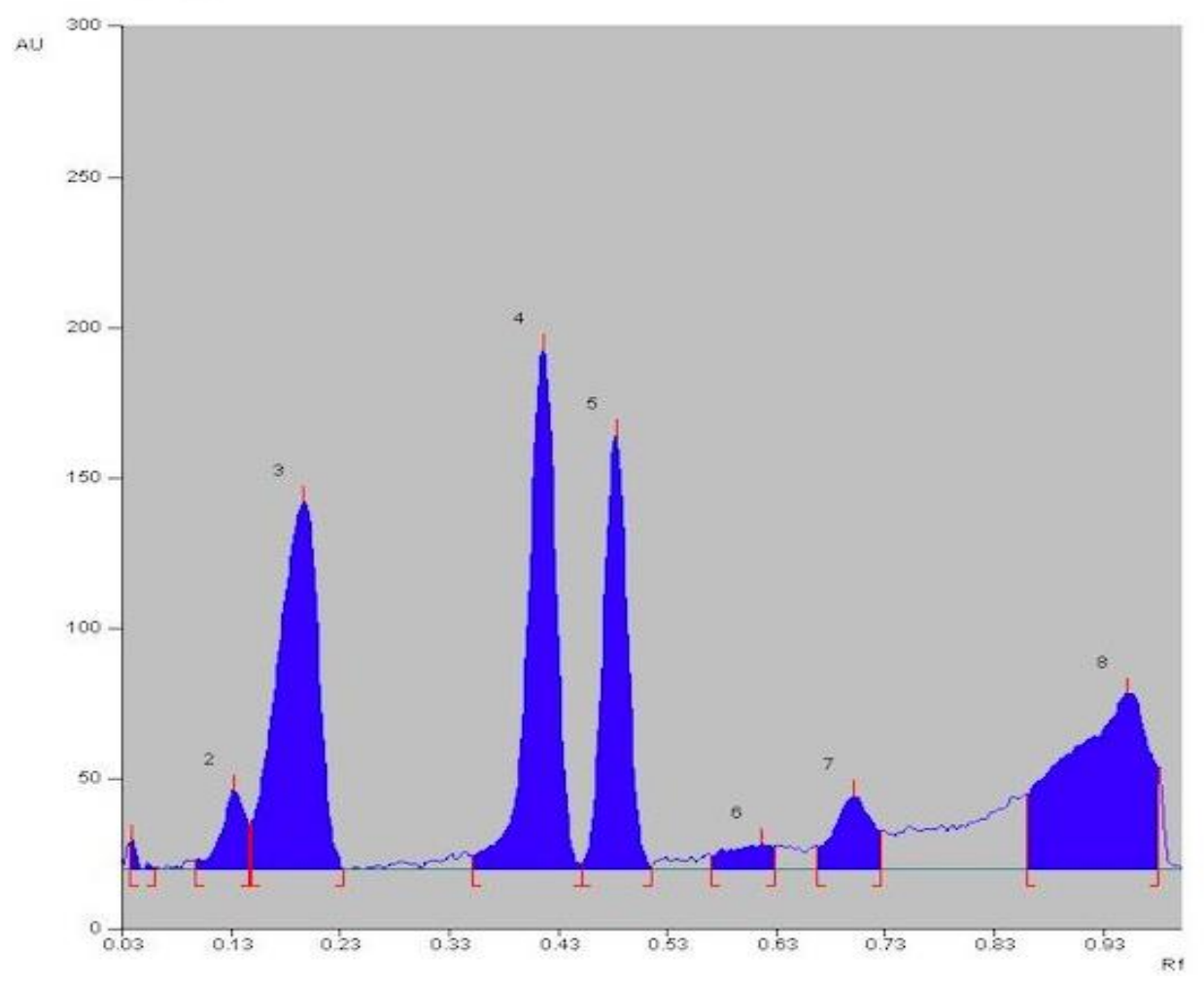

Figure 3. HPTLC chromatogram obtained by spiking 5-HMF (5) and IS (4) solutions to toxin free baby food.

Although there was no research that studies 5-HMF using HPTLC in fruit-based baby foods, only limited studies were conducted by HPTLC for determination of 5-HMF in carbohydrate-rich food [11-13, 16,17]. A report published consist of 17 honey samples of different botanical origin from 12 countries [16]. The developed HPTLC method was modified to achieve higher sensitivity and to avoid matrix interference in dense matrices such as honey. The quantification limit was found as $4 \mathrm{mg} / \mathrm{kg}$ which allowed for rapid quantification of 5-HMF in honey in consistent with the present study [16].

An HPTLC study was designed for analysis of 5-HMF in seven types of fruit wine and three types of vinegar in Istanbul market. The recovery values for this developed method were found in the range $95-112 \%$. The limits of detection and quantification of the method were found $0.045 \mathrm{ng} / \mathrm{mL}$ and $0.125 \mathrm{ng} / \mathrm{mL}$, respectively. The tested samples were found to contain 5-HMF in the ranges 0.5 to 13.2 $\mathrm{ng} / \mu \mathrm{L}$ for wines and 1.0 to $33.1 \mathrm{ng} / \mu \mathrm{L}$ for vinegar. According to study results the literature, detection limit values was lower than presented study, it should be remembered that the vinegar and wine matrices were softer than a complex matrix such as fruit-based baby food [17].

The similar method development with improved separation and sensitivity limit were achieved for 5-HMF by modified plate size and thickness as well as changing the detectors (UV, MS - SIM/TIC) [11-13]. 
Various studies with less or more sensitive analytical methods for 5-HMF were presented in Table 3 and similar ones were discussed above. Recovery values of this study were found lower than some studies represented in Table 3, but it was assumed within acceptable limits compared to guideline [34].

\subsection{5-HMF Concentrations of Authentic Food Samples}

The validated HPTLC method was applied to 58 marketed products and the 5-HMF concentrations were found in $48(82.76 \%)$ products in the range between $13.12-28.90 \mathrm{mg} / \mathrm{kg}$ with a mean value of $20.23 \mathrm{mg} / \mathrm{kg}$. As a main subject of this study, current (Table 2) and previous studies (Table 3) related to 5-HMF contamination in baby food were summarized. The obtained values here were consistent with those for different formulas in the literature. Besides 5-HMF determined products did show any correlation neither with the fruit type nor brand name of the baby food specified in the "2.2. Sample Collection and Processing" section. However, 5-HMF level was found to be 21.45-28.90 $\mathrm{mg} / \mathrm{kg}$ in products containing only apple $(15.5 \%)$.

Certain undesirable chemical reactions take place and some compounds are formed during the thermal process such as heating, baking, roasting, grilling, canning, hydrolysis or fermentation. Among these compounds, some of them are carcinogenic, such as acrylamide and furans [2].

Ready-made baby foods consist of milk, fruit, and cereal. Fruit-based products are highly sensitive to Maillard reactions due to their acidity, so commercial samples present a wide range of 5HMF contents [20,30]. Moreover, the presence of 5-HMF formation was investigated in expired baby cough syrups under deteriorated storage conditions [5].

There were limited studies on 5-HMF contaminated baby food in literature [29-33]. One of them was a HPLC study conducted for evolution of 5-HMF and furosine content in jams and fruit-based baby foods. It was conducted under the controlled storage duration in order to assess the reliability of these parameters as quality indicators. 5-HMF content was found in the range between 1 to $65 \mathrm{mg} / \mathrm{kg}$ [30].

Another study from the same region in 2006 evaluated 5-HMF level in baby food and, this was expressed a comparison of developed LC-MS and HPLC-UV methods in order to use in the investigation on a wide variety of processed baby foods including breads, biscuits, and adopted and follow-on formulas, as well as fruited fresh cheeses and yogurts [20]. According to the results, 5-HMF content of 16 commercial baby products were found in the range of $0.17-57.18 \mathrm{mg} / \mathrm{kg}$ with Solid Phase Extraction (SPE) after acetic acid treatment. It was concluded that more sensitive methods were needed to determine toxic compounds into various food matrices. The determined lower limit concentrations were in consistent but determined upper limit concentration were higher than the presented study.

Table 2. 5-HMF amount found in selected baby products

\begin{tabular}{lcl}
\hline Food commodities & $\begin{array}{c}\text { HMF content } \\
(\mathbf{m g} / \mathbf{k g})\end{array}$ & Reference \\
Baby syrup (expired drug) & $2.24-18.24$ & {$[5]$} \\
Baby food (milk based) & $0.18-0.43$ & {$[20]$} \\
Baby food (cereal based) & $0.17-57.18$ & {$[20]$} \\
Baby food (milk-based) & $0.039-0.366$ & {$[23]$} \\
Baby food (fruit-based) & $1.0-65.0$ & {$[30]$} \\
Baby food (formula based) & $6.7-13.3$ & {$[33]$} \\
Baby food (fruit-based) & $13.12-28.90$ & Present study \\
\hline
\end{tabular}


Türkmen, J. Chem. Metrol. 14:1 (2020) 52-62

Table 3. Comparison of recent studies for 5-HMF determination by progressive techniques

\begin{tabular}{|c|c|c|c|c|c|c|c|c|}
\hline Method & Ext. Method & $\begin{array}{c}\text { Food } \\
\text { commodities }\end{array}$ & LODs & LOQs & Linear range & $\mathbf{R}^{2}$ & Recovery & Reference \\
\hline MECK-UV & Direct application & Honey & $0.09 \mu \mathrm{g} / \mathrm{mL}$ & $0.31 \mathrm{mg} / \mathrm{kg}$ & $10-80 \mathrm{mg} / \mathrm{kg}$ & 0.99 & $96.37-99.56 \%$ & {$[22]$} \\
\hline CE-DAD* & Direct application & Honey & $0.09 \mu \mathrm{g} / \mathrm{mL}$ & $0.31 \mathrm{mg} / \mathrm{kg}$ & $10-800 \mathrm{mg} / \mathrm{L}$ & 0.995 & $90.44-110.37 \%$ & {$[21]$} \\
\hline NMR & Direct application & Caffee & $0.30 \mathrm{mg} / \mathrm{g}$ & - & - & - & - & {$[24]$} \\
\hline LC-MS & $\begin{array}{c}\text { Carrez addition } \\
\text { SPE }\end{array}$ & Baby food & $0.005 \mu \mathrm{g} / \mathrm{mL}$ & - & $0.05-2 \mathrm{mg} / \mathrm{kg}$ & 0.99 & $91.8-94.7 \%$ & {$[20]$} \\
\hline HPLC-UV & Carrez addition & Baby food & - & - & - & 0.99 & - & {$[30]$} \\
\hline HPLC-UV & Total Dry Extract & Beer & $0.012 \mu \mathrm{g} / \mathrm{mL}$ & $0.036 \mathrm{mg} / \mathrm{L}$ & $1.0-128.0 \mathrm{~g} / \mathrm{L}$ & 0.999 & $93-102 \%$ & {$[19]$} \\
\hline HPLC-DAD & Direct application & $\begin{array}{c}\text { Syrup / } \\
\text { Expired drug }\end{array}$ & $0.011 \mu \mathrm{g} / \mathrm{mL}$ & $0.036 \mu \mathrm{g} / \mathrm{mL}$ & $1.0-50.0 \mu \mathrm{g} / \mathrm{mL}$ & 0.999 & - & {$[5]$} \\
\hline $\begin{array}{c}\text { HPTLC-UV } \\
\text { and MS }\end{array}$ & Direct application & Honey & $0.58 \mathrm{mg} / \mathrm{kg}$ & $2.0 \mathrm{mg} / \mathrm{kg}$ & $0.8-80 \mathrm{ng} / \mathrm{spot}$ & 0.9998 & - & [11] \\
\hline HPTLC-UV & LL & Vinegar, Wine & $0.045 \mathrm{ng} / \mathrm{mL}$ & $0.125 \mu \mathrm{g} / \mathrm{kg}$ & $0.5-20.0 \mu \mathrm{g} / \mathrm{L}$ & 0.9968 & $95-112 \%$ & {$[17]$} \\
\hline HPTLC & SPE & Fruit juices & $4.0 \mathrm{ng} / \mathrm{spot}$ & - & - & 0.99 & - & {$[12]$} \\
\hline HPTLC-UV & LL & Honey & $2.0 \mathrm{ng} / \mathrm{mL}$ & $4.0 \mu \mathrm{g} / \mathrm{kg}$ & $4.0-60.0 \mu \mathrm{g} / \mathrm{kg}$ & 0.9994 & $100.2-115.2 \%$ & [16] \\
\hline $\begin{array}{c}\text { HPTLC } \\
\text { UTLC }\end{array}$ & LL & Honey & $\begin{array}{l}34-65 \mathrm{ng} / \mathrm{spot} \\
14-27 \mathrm{ng} / \mathrm{spot}\end{array}$ & - & - & $\begin{array}{l}0.9997 \\
0.9994\end{array}$ & - & {$[13]$} \\
\hline HPTLC-UV & QUECHERS & Baby food & $1.54 \mathrm{ng} / \mathrm{g}$ & $4.67 \mathrm{ng} / \mathrm{g}$ & $10-750 \mu \mathrm{g} / \mathrm{kg}$ & 0.9973 & $83.65-96.02 \%$ & $\begin{array}{l}\text { Present } \\
\text { method }\end{array}$ \\
\hline
\end{tabular}

*DAD: Diode Array Detector; Ext.: Extraction 


\section{Conclusions}

It should be noted that this developed method offers a parallel separation of $\sim 25$ products on the same plate and simultaneous evaluation of all the samples within a short time and a less organic solvent use. QuEChERS method after acidified treatment offers a good stability for 5-HMF compound, potent extract and easy applicability.

It is easily understandable that storage conditions were also affect the formation 5-HMF in addition to processing [5]. Despite 5-HMF has been known one of the unavoidable compounds due to thermal process, we believe that transportation of baby formula in appropriate circumstances should be given more priority in hot climate conditions.

This was the first study that 5-HMF was determined by HPTLC with A-QuEChERS extraction in fruit-based baby food products in Istanbul. Although the concentration of $82.76 \%$ of the 5-HMF detected products was found to be below the legal limit, the results revealed that a new regulation should be made in fruitbased food considering the baby exposure limit. Satisfactory results in relation to linearity, selectivity, precision and accuracy were obtained, which confirmed that the proposed method was suitable for regulatory requirements. As a general conclusion, the analytical performance of the method, particularly low cost and simple sample pretreatment, verifies its potential applicability for routine and automated analysis of 5-HMF in the quality control of food products.

\section{Acknowledgments}

This research was supported by the Research Fund of the Istanbul University - Cerrahpasa, with the Project No. TYL-2016-20513. And author also would like to thank to Merve Kuloglu and Tugba Tekin for their technical support.

\section{Supporting Information}

Supporting information accompanies this paper on http://www.acgpubs.org/journal/journal-ofchemical-metrology

\section{ORCID}

Zeynep Turkmen: 0000-0002-8250-7520

\section{References}

[1] C. Crews and L. Castle (2007). A review of the occurrence, formation and analysis of furan in heatprocessed foods, Trend. Food Sci. Technol. 18 (7), 365-372.

[2] E. Capuano and V. Fogliano (2011). Acrylamide and 5-hydroxymethylfurfural (HMF): A review on metabolism, toxicity, occurrence in food and mitigation strategies, LWT Food Sci. Technol. 44(4), 793-810.

[3] C. Svendsen, T. Husoy, H. Glatt, J.E. Paulsen and J. Alexander (2009). 5-Hydroxymethylfurfural and 5sulfooxymethylfurfural increase adenoma and flat ACF number in the intestine of Min/+ mice, Anticancer Res. 29(6), 1921-1926.

[4] K. Abraham, R. Gürtler, K. Berg, G. Heinemeyer, A. Lampen and K.E. Appel, (2011).Toxicology and risk assessment of 5-Hydroxymethylfurfural in food, Mol. Nut. Food Res. 55(5), 667-678.

[5] S. Unuvar (2018). Determination of 5-hydroxymethylfurfural (5-HMF) in expired pharmaceutical syrups by using HPLC-DAD method, J. Turk. Chem. Soc. Section A: Chem. 5(3), 1431-1440.

[6] D. Carballo, J.C. Moltó, H. Berrada and E. Ferrer (2018). Presence of mycotoxins in ready-to-eat food and subsequent risk assessment, Food Chem. Toxicol. 121, 558-565.

[7] P. Wang, Y. Chen, X. Xu, B. Hellmann, C. Huang, Y. Bai and Z. Jin (2019). HPTLC screening of folic acid in food: In situ derivatization with ozone-induced fluorescence, Food Anal. Method. 12(2), 431-439. 
[8] Y. Chen, C. Huang, B. Hellmann and X. Xu (2020). HPTLC-densitometry determination of riboflavin fortified in rice noodle: Confirmed by SERS-fingerprint, Food Anal. Method. 13, 718-725.

[9] Z. Turkmen, S. Mercan and S. Cengiz (2013). An HPTLC method for the determination of oleandrin in Nerium plant extracts and its application to forensic toxicology, J. Planar Chrom. 26(3), 279-283.

[10] Z. Turkmen and O. Kurada (2020). Rapid HPTLC determination of Patulin in marketed products of Baby Nutrition in Turkey and their toxicity evaluation, J. Planar Chromat. 33(3) (In press) doi: 10.1007/s00764020-00032-1.

[11] E.S. Chemetsova, I.A. Revelsky and G.E. Morlock (2011). Fast quantitation of 5-hydroxymethyl-furfural in honey using planar chromatography, Anal. Bioanal. Chem. 401, 325-332.

[12] A. Przybylska and G. Bazylak (2013). A comparison of the selectivity of nano-HPTLC systems used for determination of patulin in fruit juices from the internet stores and pharmacies, Curr. Issues Pharm. Med. Sci. 26(2), 155-159.

[13] S. Kirchert, M. Schulz, M. Oberle and G.E. Morlock (2019). Development of a new particulate 4- $\mu \mathrm{m}$ adsorbent layer for ultrathin-layer chromatography (miniaturized chromatogram), J. Chrom. A. 1587, 247255.

[14] N.M. Bhatt, V.D. Chavada, M. Sanyal and P.S. Shrivastav (2019). Densitometry and indirect normal- phase HPTLC- ESI- MS for separation and quantitation of drugs and their glucuronide metabolites from plasma, Biomed. Chromat. 33(10), 1-12.

[15] X.Y. Li, Y. Li, Z.J. Qian, M.M. Kim and S.K. Kim (2009). In vitro antioxidant activity of 5-HMF isolated from marine red alga Laurencia undulata in free-radical-mediated oxidative systems, J. Microbiol. Biotechnol. 19(11), 1319-1327.

[16] A. Hoštálková, I. Klingelhöfer and G.E. Morlock (2013). Comparison of an HPTLC method with the Reflectoquant assay for rapid determination of 5-hydroxymethylfurfural in honey, Anal. Bioanal. Chem. 405(28), 9207-9218.

[17] H. Kurtbay, I. Kaynak, S. Bozkurt and M. Merdivan (2009). Densitometric HPTLC analysis of the 5hydroxymethylfurfural content of Turkish fruit wines and vinegars, J. Planar Chromat. 22(5), 363-366.

[18] J.P. Yuan and F. Chen (1999). Simultaneous separation and determination of sugars, ascorbic acid and furanic compounds by HPLC — dual detection, Food Chem. 64(3), 423-427.

[19] M. Castellari, E. Sartini, U. Spinabelli, C. Riponi and S. Galassi (2001). Determination of carboxylic acids, carbohydrates, glycerol, ethanol, and 5-HMF in beer by high-performance liquid chromatography and UVrefractive index double detection, J. Chromat Sci. 39(6), 235-238.

[20] V. Gokmen, and H.Z. Senyuva (2006). Improved method for the determination of hydroxymethylfurfural in baby foods using Liquid chromatography-mass spectrometry, J. Agric. Food Chem. 54, 2845-2849.

[21] F.C. Biluca, F. Della Betta, G.P. de Oliveira, L.M. Pereira, L.V. Gonzaga, A.C.O. Costa and R. Fett (2014). 5-HMF and carbohydrates content in stingless bee honey by CE before and after thermal treatment, Food Chem. 159, 244-249.

[22] V.M. Rizelio, L.V. Gonzaga, G.D.S.C. Borges, G.A. Micke, R. Fett and A.C.O. Costa (2012). Development of a fast MECK method for determination of 5-HMF in honey samples, Food Chem. 133(4), 1640-1645.

[23] Y. Cui, X. Shi, Y. Tang, Y. Xie and Z. Du (2020). The effects of heat treatment and fermentation processes on the formation of furfurals in milk-based dairy products using a QuEChERS technique followed by gas chromatography coupled with triple quadrupole mass spectrometry, Food Chemistry, 313, 125930.

[24] G. del Campo, I. Berregi, R. Caracena and J. Zuriarrain (2010). Quantitative determination of caffeine, formic acid, trigonelline and 5-(hydroxymethyl) furfural in soluble coffees by ${ }^{1} \mathrm{H}$ NMR spectrometry, Talanta 81(1-2), 367-371.

[25] Directive 2001/110/EC of the Council of the European Communities of 20 December 2001 relating to honey, Off. J. Eur. Commun. L10, 47-52.

[26] Turkish Food Codex, Honey Communique (No: 2005/49), https://www.resmigazete.gov.tr/ eskiler/2005/12/20051217-9.htm (Last access 20.01.2020)

[27] R.A. Oral (2006). Determination of hydroxymethylfurfural (HMF) content in some foods, changing of HMF level during storage and reduction with biological method, Master Thesis, Erciyes University, Kayseri, Turkey. 
[28] Z.E. Metin (2014). Determination of hydroxymethylfurfural levels of pomegranate sour, pomegranate sour sauce and grape molasses sold in Ankara markets, Master Thesis, Hacettepe University, Ankara, Turkey.

[29] M. Jestoi, T. Järvinen, E. Järvenpää, H. Tapanainen, S. Virtanen and K. Peltonen (2009). Furan in the babyfood samples purchased from the Finnish markets-determination with SPME-GC-MS, Food Chem. 117(3), 522-528.

[30] M. Rada-Mendoza, M.L. Sanz, A. Olano and M. Villamiel (2004). Formation of hydroxymethylfurfural and furosine during the storage of jams and fruit-based baby foods, Food Chem. 85(4), 605-609.

[31] M. Rada-Mendoza, A. Olano and M. Villamiel (2002). Determination of hydroxymethylfurfural in commercial jams and in fruit-based baby foods, Food Chem. 79(4), 513-516.

[32] E. Ferrer, A. Alegría, R. Farré, P. Abellán and F. Romero (2005). High-performance liquid chromatographic determination of furfural compounds in baby formulas during full shelf-life, Food Chem. 89(4), 639-645.

[33] E. Ferrer, A. Alegria, R. Farre, P. Abellan and F. Romero (2002). High-performance liquid chromatographic determination of furfural compounds in baby formulas: Changes during heat treatment and storage, J Chrom. A. 947(1), 85-95.

[34] S.J. Lehotay, K.A. Son, H. Kwon, U. Koesukwiwat, W. Fu, K. Mastovska and N. Leepipatpiboon (2010). Comparison of QuEChERS sample preparation methods for the analysis of pesticide residues in fruits and vegetables, J. Chrom. A 1217(16), 2548-2560.

[35] FDA, (CDER, CVM, and ORA), PAT (2004). A Framework for Innovative Pharmaceutical Development, Manufacturing, and Quality Assurance, guidance for industry, September 2004, Rockville, MD.

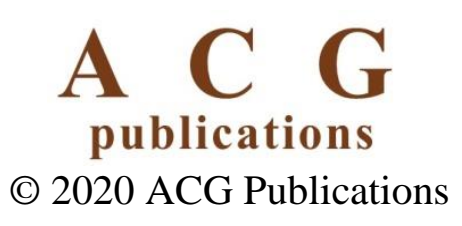

